\title{
Erratum to: Differential effects of enalapril and losartan on body composition and indices of muscle quality in aged male Fischer $344 \times$ Brown Norway rats
}

\author{
Christy S. Carter - Silvia Giovannini • Dong-Oh Seo • Jameson DuPree • \\ Drake Morgan • Hae Young Chung • Hazel Lees • Michael Daniels • \\ Gene B. Hubbard • Shuko Lee • Yuji Ikeno • Thomas C. Foster • \\ Thomas W. Buford • Emanuele Marzetti
}

Published online: 6 April 2011

(C) American Aging Association 2011

\section{Erratum to: AGE}

$$
\text { DOI 10.1007/s11357-010-9196-y }
$$

Unfortunately, the article was published with the second author's name mispelled and should appear as Silvia Giovannini.

The online version of the original article can be found at http:// dx.doi.org/10.1007/s11357-010-9196-y.

C. S. Carter $(\bowtie) \cdot$ S. Giovannini $\cdot$ D.-O. Seo $\cdot$ J. DuPree $\cdot$

H. Lees $\cdot$ T. W. Buford $\cdot$ E. Marzetti

Department of Aging and Geriatric Research,

Institute on Aging, University of Florida,

Gainesville, FL 32610, USA

e-mail: ccarter@aging.ufl.edu

S. Giovannini

Department of Gerontology, Geriatrics and Physical

Sciences, Catholic University of the Sacred Heart,

Rome, Italy

D. Morgan

Department of Psychiatry, University of Florida,

Gainesville, FL 32610, USA

\section{H. Y. Chung}

Department of Pharmacy, Longevity Science and

Technology Institutes, Research Institute for Drug

Development, Pusan National University,

Geumjeong-gu,

Busan 609-735, South Korea
M. Daniels

Department of Statistics, University of Florida, Gainesville, FL 32610, USA

G. B. Hubbard · Y. Ikeno

Barshop Institute and Department of Pathology, University of Texas Health Science Center,

San Antonio, TX 78245, USA

S. Lee $\cdot$ Y. Ikeno

Audie Murphy VA Hospital (STVHCS),

San Antonio, TX 78245, USA

T. C. Foster

Department of Neuroscience, University of Florida, Gainesville, FL 32610, USA

E. Marzetti

Department of Orthopedics and Traumatology,

Catholic University of the Sacred Heart,

Rome, Italy 